\title{
Use of a Nitrate-Nonutilizing Mutant and Selective Media to Examine Population Dynamics of Fusarium oxysporum f. sp. spinaciae in Soil
}

\author{
Toshiaki Takehara, Katsuto Kuniyasu, Mitsutaka Mori, and Hiroshi Hagiwara
}

First, second, and fourth authors: Soil-borne Disease Laboratory, National Agricultural Research Center, Tsukuba, Ibaraki 305-8666, Japan; and third author: Kagawa Prefectural Agricultural Experiment Station, Takamatsu, Kagawa 761-8078, Japan.

Current address of K. Kuniyasu: 14-4 Higashi-tsuwa, Tsuchiura, Ibaraki 300-0067, Japan.

Current address of H. Hagiwara: National Agricultural Research Center for Tohoku Region, Morioka, Iwate 020-0198, Japan.

Accepted for publication 30 April 2003.

\begin{abstract}
Takehara, T., Kuniyasu, K., Mori, M., and Hagiwara, H. 2003. Use of a nitrate-nonutilizing mutant and selective media to examine population dynamics of Fusarium oxysporum f. sp. spinaciae in soil. Phytopathology 93:1173-1181.

Determining the population density of the spinach wilt pathogen $F u$ sarium oxysporum f. sp. spinaciae in soil with conventional Fusariumselective media is quite difficult because nonpathogenic strains of $F$. oxysporum also grow on those media and are indistinguishable from the pathogen. Therefore, a nitrate-nonutilizing (nit) mutant of the pathogen and corresponding selective media were tested in an experimental approach to determine the population density of the pathogen. Colony forming units of the pathogen were countable after soil-dilution plating

type Fusarium-selective medium, GMBP. By combining nit mutant- and wild-type-selective media, the population densities of pathogenic and nonpathogenic $F$. oxysporum in the same soil could be measured selectively. This method was useful in studying population dynamics of the pathogen after different soil treatments. Soil disinfested with hot water or chloropicrin was amended with the nit mutant pathogen, and subsequent changes in population densities of the pathogen were compared with those in nontreated field soil. The pathogen rapidly proliferated in disinfested soil and wilt developed faster than in nontreated soil. When a nonpathogenic isolate of $F$. oxysporum was added at high density to sterilized soil prior to the pathogen, growth of the pathogen was greatly suppressed. Nonpathogenic $F$. oxysporum could not, however, reduce the density of preexisting pathogen.
\end{abstract} onto nit mutant-selective media MMCPA, CMP, and CGMBP. Colony forming units of wild-type Fusarium spp. were countable using a wild-

Fusarium wilt of spinach, caused by Fusarium oxysporum f. sp. spinaciae, is a major production constraint in spinach-growing areas in the United States, Japan, Canada, and Sweden $(2,13)$. In Japan, soil fumigation with chloropicrin or methyl bromide has been commonly used to control the disease. Soil disinfestation with hot water (8) has been proposed as a new alternative.

Even after soil disinfestation, severe infection of spinach may occur after several plantings (4). This infection is thought to be due to the proliferation of remaining or reintroduced pathogen in disinfested soil $(16,19)$, but no study has actually reported changes in population density.

To determine pathogen density in soil, specific strains of pathogenic $F$. oxysporum must be identified by differentiating them from other formae speciales and races or nonpathogenic strains of F. oxysporum. On conventional Fusarium-selective media $(7,14$, 26) used in the soil-dilution plate technique, colonies of pathogens cannot be distinguished from other Fusarium colonies. The inoculation tests with host plants or race-differential cultivars for each colony that are needed to identify them are too labor- and time-intensive to be practical.

Nitrate-nonutilizing (nit) mutants of $F$. oxysporum, tolerant to chlorate, can be selectively reisolated from soil and plants using chlorate-containing media $(3,20,22)$. We have generated nit mutants of the spinach wilt pathogen and reisolated them from soil on selective media (21-23). Based on these studies, we compared the proliferation of the pathogen added to soil disinfested with hot

Corresponding author: T. Takehara; E-mail address: toshi@ affrc.go.jp

Publication no. P-2003-0708-01R

(C) 2003 The American Phytopathological Society
Additional keywords: hot-water disinfestation of soil. water and chloropicrin or pretreated with nonpathogenic $F$. oxysporum with that in nontreated soil. The objectives of this study were to (i) examine the applicability of the nit mutant and its selective media for determining the population density of the spinach wilt pathogen in soil; (ii) examine the growth of the spinach wilt pathogen and disease occurrence in soil treated with hot water or chloropicrin, compared with nontreated field soil; and (iii) determine if pretreatment of soil with a nonpathogenic $F$. oxysporum delays reinfestation by the pathogen. Here, we report the successful use of nit mutants for determining pathogen density in soil and for studying the influence of soil treatments on the subsequent proliferation of the pathogen.

\section{MATERIALS AND METHODS}

Fungal strains. We used Spin-2 (wild type, MAFF GeneBank Accession No. 103060) and M2-1 (nit mutant derived from Spin2: phenotype nitl) (23) as pathogenic strains of $F$. oxysporum $\mathrm{f}$. sp. spinaciae. M2-1 is comparable to Spin-2 in growth and pathogenicity. We used S1HI1-W (wild type) and NA-12 (nit mutant derived from S1HI1-W: phenotype nit1) as nonpathogenic strains of $F$. oxysporum. Strain S1HI1-W was a contribution from Y. Akasaka, Iwate Horticultural Experiment Station, Japan (at that time). Isolated from a spinach root, it suppresses Fusarium wilt of spinach (1). Methods to generate nit mutants are described elsewhere (21). The pathogenic strains of $F$. oxysporum are abbreviated as PF and nonpathogenic strains of $F$. oxysporum as NPF.

Soil. All experiments used field soil from the National Agricultural Research Center (NARC) (i.e., low-humic andosols having no history of spinach planting). Before each experiment, the soil was processed as described below. 
Chloropicrin-treated soil. A field plot was treated with chloropicrin on 16 September 1993 (treated area: $200 \mathrm{~m}^{2}$ ) and 5 September 2001 (treated area: 3 plots of $3 \mathrm{~m}^{2}$ ). After tilling and preparing the field plot, $15-\mathrm{cm}$-deep holes were made in every $900 \mathrm{~cm}^{2}$ (30 by $30 \mathrm{~cm}$ ), $3 \mathrm{ml}$ of chloropicrin $(80 \%)$ was injected into each hole, which was immediately filled with soil, and the entire plot was covered with transparent polyethylene film. Soil (down to $10 \mathrm{~cm}$ from soil surface) was collected 13 days after treatment in the 1993 experiment and 9 days after treatment in the 2001 experiment.

Hot-water-treated soil. As described for earlier experiments $(8,9)$, hot water was sprinkled on the soil surface until the soil temperature reached $>55^{\circ} \mathrm{C}$ at a depth of 20 to $30 \mathrm{~cm}$. Soil (down to $10 \mathrm{~cm}$ from soil surface) was collected 13 days after treatment in the 1993 experiment and 9 days after treatment in the 2001 experiment.

Hot-water treatment in the 1993 experiment. A field plot (10 by $20 \mathrm{~m}$ ) was disinfested with hot water on 16 September 1993. Hot water $\left(90\right.$ to $95^{\circ} \mathrm{C}$ ) was produced using a soil sterilizer (steam boiler) with a thermal output of 160,000 kcal/h (EC-350; Ishihara Kougyousho Co., Hamamatsu, Japan) and a steam-water thermal converter (Ebara Yutori Setto TB-880-10; Ebara Boiler Co., Fujisawa, Japan). The steam pressure of the boiler was set at 4.0 to $5.0 \mathrm{~kg} / \mathrm{cm}^{2}$ and steam temperature at 150 to $155^{\circ} \mathrm{C}$. The steam-discharge valve was fully opened, and tap water was heated to 90 to $95^{\circ} \mathrm{C}$ with the thermal converter. A relatively heat-tolerant, horizontally sprinkling-type, plastic sprinkling tube (Sumisansui R Wing; Sumika Agrotech Co. Ltd., Osaka, Japan) with an inside diameter of $3.4 \mathrm{~cm}$ was used to sprinkle hot water on the soil. The tube had two pinholes (diameter, $0.25 \mathrm{~mm}$ ) every $12 \mathrm{~cm}$ in a zigzag pattern on either side of the upper surface of the tube. Half of the pinholes were enlarged to $1 \mathrm{~mm}$ with heated needles to hasten the sprinkling. The tubes were laid in parallel on the soil surface (with pinholes upward) at intervals of $50 \mathrm{~cm}$; transparent polyethylene film then was laid over them to cover the entire plot, and $75 \mathrm{liter} / \mathrm{m}^{2}$ of the hot water was sprinkled on the soil surface. After sprinkling, the polyethylene film was kept on for 12 days to retain heat.

Hot water treatment in the 2001 experiment. The treatment (5 September 2001) was similar to that of 1993, except for the following points. Three replicate plots of $3 \mathrm{~m}^{2}(1$ by $3 \mathrm{~m})$ each were treated separately. Hot water was produced directly by a hotwater soil-sterilizer with thermal output of 250,000 kcal/h (BW-30; Marubunseisakusho Inc., Hamamatsu, Japan) and hot water sprinkled at 200 liter $/ \mathrm{m}^{2}$. The pinholes in the sprinkling tube (Sumisansui R Wing) were not enlarged.

Media and soil-dilution plating. The media listed in Table 1 were used in soil-dilution plating to selectively isolate nit mutants or wild-type Fusarium spp. Media MMCPA (22), CMP, and CGMBP (20) were used to detect nit mutants in soil. MMCPA is based on the FMMCPA of Hadar et al. (3), but has lower concentrations of $\mathrm{KClO}_{3}$ and pentachloronitrobenzene (PCNB) and lacks chloramphenicol. CMP is MMCPA amended with chloramphenicol and miconazole nitrate. CGMBP was made by replacing sucrose in CMP with galactose and adding boric acid, based on the modified MMCPA of Ueda et al. (27). GMBP medium (20) was used to detect wild-type Fusarium spp.; nit mutants weakly grow on this medium, but their colonies are barely visible. To detect Fusarium spp. in general (nit + wild), we used Komada's Fusarium-selective medium (KM) (7) with reduced PCNB $(75 \%$ wettable powder) concentration $(0.25 \mathrm{~g} / \mathrm{liter})$, or PAC medium (i.e., a potato sucrose agar [PSA] medium amended with $0.25 \mathrm{~g}$ of chloramphenicol and $0.25 \mathrm{~g}$ of PCNB [75\% wettable powder] per liter, acidified to $\mathrm{pH} 3.4$ ). To detect fungi other than Fusarium spp., PAC or MMCPA was used. To detect bacteria and actinomycetes, we used 10\% PTYG agar (PTYGA) medium (25). In soil-dilution plating, $10 \mathrm{~g}$ of soil was suspended in $90 \mathrm{ml}$ of sterilized $0.05 \%$ water agar and serially diluted with $0.05 \%$ water agar, after which 0.7 to $1 \mathrm{ml}(0.1 \mathrm{ml}$ for PTYGA) of the serial dilutions were spread over solidified media in petri dishes. After dilution plating of the soil, media were incubated at $25^{\circ} \mathrm{C}$ in the dark or at room temperature for several days, and transferred to a lighted incubator at $25^{\circ} \mathrm{C}$ (except for PTYGA) to enable Fusarium colonies to develop pigment. Colonies were counted on MMCPA after 7 to 8 days, CMP after 7 to 9 days, CGMBP after 8 to 10 days, GMBP after 8 to 10 days, PAC after 5 to 7 days, KM after 6 to 8 days, and PTYGA after 3 to 5 days.

Comparison of media selectivity and rate of propagule recovery. To check media performance in the selectivity and recovery of Fusarium propagules, soil samples for Fusarium spp. detection were prepared and dilution plated on the media. The experiment was done twice. Preparation of each soil sample was as described below.

Nit mutant inoculum soil. The nit mutant strain (M2-1) of $F$. oxysporum f. sp. spinaciae was shake-cultured in potato sucrose (PS) liquid medium at $120 \mathrm{rpm}, 28^{\circ} \mathrm{C}$, for 7 days. Shake-culture suspension $(2 \mathrm{ml})$ then was added to $400 \mathrm{ml}(\approx 270 \mathrm{~g})$ of auto-

TABLE 1 . Composition of media used in this study to selectively isolate nit mutant and wild-type Fusarium spp. ${ }^{\mathrm{a}}$

\begin{tabular}{|c|c|c|c|c|}
\hline \multirow[b]{2}{*}{ Prescription } & \multicolumn{3}{|c|}{ For nit mutant } & \multirow{2}{*}{$\begin{array}{c}\text { For wild type } \\
\text { GMBP }\end{array}$} \\
\hline & MMCPA & CMP & CGMBP & \\
\hline Sucrose & $30 \mathrm{~g}$ & $30 \mathrm{~g}$ & ... & $\ldots$ \\
\hline Galactose & $\ldots$ & $\ldots$ & $30 \mathrm{~g}$ & $30 \mathrm{~g}$ \\
\hline $\mathrm{KH}_{2} \mathrm{PO}_{4}$ & $1 \mathrm{~g}$ & $1 \mathrm{~g}$ & $1 \mathrm{~g}$ & $1 \mathrm{~g}$ \\
\hline $\mathrm{MgSO}_{4} \cdot 7 \mathrm{H}_{2} \mathrm{O}$ & $0.5 \mathrm{~g}$ & $0.5 \mathrm{~g}$ & $0.5 \mathrm{~g}$ & $0.5 \mathrm{~g}$ \\
\hline $\mathrm{KCl}$ & $0.5 \mathrm{~g}$ & $0.5 \mathrm{~g}$ & $0.5 \mathrm{~g}$ & $0.5 \mathrm{~g}$ \\
\hline $\mathrm{H}_{3} \mathrm{BO}_{3}$ & $\ldots$ & $\ldots$ & $0.5 \mathrm{~g}$ & $0.5 \mathrm{~g}$ \\
\hline Agar & $20 \mathrm{~g}$ & $20 \mathrm{~g}$ & $20 \mathrm{~g}$ & $20 \mathrm{~g}$ \\
\hline Chloramphenicol & $\ldots$ & $0.25 \mathrm{~g}$ & $0.25 \mathrm{~g}$ & $0.25 \mathrm{~g}$ \\
\hline Sterile trace elements solution ${ }^{\mathrm{b}}$ & $0.2 \mathrm{ml}$ & $0.2 \mathrm{ml}$ & $0.2 \mathrm{ml}$ & $0.2 \mathrm{ml}$ \\
\hline Miconazole nitrate & & $50 \mathrm{mg}^{\mathrm{c}}$ & $50 \mathrm{mg}$ & $50 \mathrm{mg}$ \\
\hline Distilled water & 1 liter & 1 liter & 1 liter & 1 liter \\
\hline \multicolumn{5}{|l|}{ After autoclaving } \\
\hline
\end{tabular}

a nit $=$ nitrate nonutilizing and $\ldots=$ not added.

${ }^{\mathrm{b}}$ Distilled water, $95 \mathrm{ml}$; citric acid, $5 \mathrm{~g} ; \mathrm{ZnSO}_{4} \cdot 7 \mathrm{H}_{2} \mathrm{O}, 5 \mathrm{~g} ; \mathrm{FeSO}_{4} \cdot 7 \mathrm{H}_{2} \mathrm{O}, 4.75 \mathrm{~g} ; \mathrm{Fe}\left(\mathrm{NH}_{4}\right)_{2} \cdot\left(\mathrm{SO}_{4}\right)_{2} \cdot 6 \mathrm{H}_{2} \mathrm{O}, 1 \mathrm{~g} ; \mathrm{CuSO}_{4} \cdot 5 \mathrm{H}_{2} \mathrm{O}, 250 \mathrm{mg} ; \mathrm{MnSO}_{4} \cdot \mathrm{H}_{2} \mathrm{O}, 50 \mathrm{mg}$; $\mathrm{H}_{3} \mathrm{BO}_{3}, 50 \mathrm{mg}$; and $\mathrm{Na}_{2} \mathrm{MoO}_{4} \cdot 2 \mathrm{H}_{2} \mathrm{O}, 50 \mathrm{mg}$ (17).

${ }^{c}$ FLORID-D solution: $5 \mathrm{ml}$ of $10 \mathrm{mg} / \mathrm{ml}$ (Mochida Pharmaceutical Co., Ltd., Tokyo).

${ }^{\mathrm{d}} \mathrm{pH}$ was adjusted with $10 \%$ phosphoric acid solution. 
claved soil in a flask, mixed well, and incubated for 1 month at $20^{\circ} \mathrm{C}$ in the dark.

Field soil. Soil was collected on 13 June 1995 in the first experiment and 25 August 2000 in the second experiment from the same field as that used in the soil disinfestation experiment.

Field soil + nit mutant inoculum. The field soil described above was infested with the nit mutant (M2-1) inoculum soil at a low and high density. In the first experiment, the ratio of grams of field soil and inoculum soil was 19.8:0.2 and 18:2 for the low- and high-density infestations, respectively. In the second experiment, the ratio was 39.9:0.1 and 39:1 g for the low- and high-density infestations, respectively.

Proliferation of nit mutant pathogen in hot water-, chloropicrin-, and non-treated soils. First experiment (1993). Thirteen days after treatment, soil was collected from the treated and nontreated plots. The next day, each soil was placed in plastic pots (30 by $23 \mathrm{~cm}, 12 \mathrm{~cm}$ deep, $3 \mathrm{~kg}$ of soil per pot) and infested with the nit mutant pathogen (M2-1) as follows. The nit mutant M2-1 was shake-cultured in PS liquid medium at $120 \mathrm{rpm}, 28^{\circ} \mathrm{C}$, for 7 days, and the bud-cell suspension was diluted to $\approx 10^{6}$ and $10^{4}$ bud cells $/ \mathrm{ml}$. In all, $10 \mathrm{ml}$ (1-ml samples $\times 10$ spots) of the $10^{6}$ (high-density) or $10^{4}$ (low-density) inoculum (bud-cell suspension) was added to a pot of soil and mixed well to produce initial pathogen densities of $\approx 5,000$ and 50 bud cells/g of soil, respectively. The next day, 40 spinach seed (cv. Majikku-hourensou; Sakata Seed Co., Yokohama, Japan) were sown per pot and placed in a greenhouse $\left(15\right.$ to $\left.30^{\circ} \mathrm{C}\right)$ to observe disease development. Two pots were used for each treatment. Soil was sampled as described below for soil-dilution plating at 1, 13, 25, 48, and 76 days after nit mutant inoculation. Soil was sampled from five locations between spinach plants in each pot, combined $(\approx 20 \mathrm{~g}$ total), and mixed well to serve as one sample for each pot. Population densities of the nit mutant, wild-type Fusarium spp., other fungi, and bacteria were measured by the soil-dilution plate method. MMCPA medium was used to detect nit mutant and fungi other than Fusarium spp. KM was used to detect Fusarium spp. in general. The population density of wild-type Fusarium spp. was calculated by subtracting the nit mutant population from the general population of Fusarium spp. obtained on KM.

Second experiment (2001). The experimental designs and methods in the second experiment were almost the same as in the first. Soil was collected 9 days after hot water and chloropicrin treatments. One pot $(3 \mathrm{~kg})$ of soil was collected from each field plot (three plots of $3 \mathrm{~m}^{2}$ for each treatment), resulting in three replicates of pots for each treatment. Inoculum was applied only at the low density to produce an initial pathogen density of $\approx 50$ bud cells/g of soil. Spinach seed was sown at $30 \mathrm{seed} /$ pot. CMP medium was used to detect the nit mutant and PAC medium to detect Fusarium spp. in general and other fungi.

Antagonistic effect of nonpathogenic $F$. oxysporum on pathogen proliferation in sterilized soil. First experiment. Field soil (100 g) was placed in 200-ml Erlenmeyer flasks, which were then capped with double-layered aluminum foil and autoclaved at $120^{\circ} \mathrm{C}$ for $60 \mathrm{~min}$. A nonpathogenic strain of F. oxysporum (NPF: strain S1HI1-W) was shake-cultured in PS liquid medium at $28^{\circ} \mathrm{C}, 120 \mathrm{rpm}$ for 7 days, then $3 \mathrm{ml}$ of the 100 -fold diluted culture fluid $\left(1.5 \times 10^{5}\right.$ bud cells $\left./ \mathrm{ml}\right)$ was added to the sterilized soil in flasks and mixed well to produce an initial NPF density of $\approx 7 \times 10^{3}$ bud cells/g dry soil. The nit mutant pathogen (PF: strain $\mathrm{M} 2-1$ ) was cultured in PS liquid medium at $28^{\circ} \mathrm{C}, 120 \mathrm{rpm}$ for 8 days (to $3.5 \times 10^{7}$ bud cells $/ \mathrm{ml}$ ), and $1 \mathrm{ml}$ of the 30 -fold or 3,000-fold diluted culture fluid was inoculated into the soil 8 days after NPF pretreatment to produce an initial PF density of $\approx 1.8 \times$ $10^{2}$ and $1.8 \times 10^{4}$ bud cells/g dry soil, respectively. Soil with no NPF pretreatment also was amended with PF in the same way. No spinach seed were sown and two flasks per treatment were incubated at $25^{\circ} \mathrm{C}$ in the dark. At 6 and 13 days after PF inoculation, soil in flasks was aseptically stirred, and soil samples $(10 \mathrm{~g})$ were taken to measure the population densities of PF and NPF by soildilution plating on CGMBP and GMBP media. The caps were kept on the flasks throughout the experiment, except during the addition of NPF and PF and sampling of soil. Water content of soil throughout was $\approx 35 \%$ (wt/wt).

Second experiment. The experimental design was the same as in the first experiment, except for the following details. Soil $(200 \mathrm{~g})$ was placed in 300-ml Erlenmeyer flasks. The initial density for NPF was adjusted to $\approx 10^{4}$ bud cells/g dry soil, and for PF to $\approx 10^{2}$ and $10^{4}$ bud cells/g dry soil. Soil ( $15 \mathrm{~g}$ ) was sampled immediately after PF inoculation, and 6, 13, and 28 days after PF inoculation. At the end of the experiment, soil in all flasks was checked for contamination by fungi other than Fusarium spp. or by bacteria using soil-dilution plating on PAC and PTYGA media.

Third experiment. The third experiment was identical to the second, except for the use of a nit mutant of NPF and a wild type of PF. A nit mutant of NPF (strain NA-12) was added 8 days before the wild-type PF (strain Spin-2). Population densities of PF and NPF were measured by soil-dilution plating on GMBP and CGMBP, respectively.

After the completion of all experiments, nit mutant-infested soil was sterilized before disposal to prevent release of the mutant strains into the natural environment.

Statistical analyses. StatView for Windows (version 5.0; SAS Institute Inc., Cary, NC) was used for statistical analysis. Population density data were transformed before analysis using the

TABLE 2. Number of colonies of nit mutant Fusarium oxysporum, wild-type Fusarium spp., and other fungi on five selective media (first experiment) ${ }^{\mathrm{a}}$

\begin{tabular}{|c|c|c|c|c|c|}
\hline Soil sample & MMCPA & CMP & CGMBP & GMBP & $\mathrm{KM}^{\mathrm{b}}$ \\
\hline \multicolumn{6}{|l|}{ Fusarium spp. ${ }^{\mathrm{c}}$} \\
\hline Field soil $^{\mathrm{d}}$ & 0 & 0 & 0 & $45.0 \pm 6.2$ & $40.2 \pm 6.9$ \\
\hline nit mutant inoculum ${ }^{\mathrm{e}}$ & $143.6 \pm 9.4$ & $142.6 \pm 7.3$ & $119.6 \pm 9.3$ & 0 & $153.4 \pm 21.1$ \\
\hline Field soil + nit (low density) ${ }^{\mathrm{f}}$ & $14.8 \pm 3.3$ & $14.6 \pm 3.0$ & $13.4 \pm 3.9$ & $45.0 \pm 5.6$ & $56.6 \pm 8.5$ \\
\hline Field soil + nit (high density)g & $109.8 \pm 7.6$ & $119.8 \pm 12.5$ & $95.8 \pm 15.0$ & $38.2 \pm 7.3$ & $156.6 \pm 14.3$ \\
\hline \multicolumn{6}{|l|}{ Other fungi ${ }^{\text {h }}$} \\
\hline Field soil ${ }^{\mathrm{d}}$ & $97.2 \pm 8.2$ & $37.2 \pm 7.0$ & $2.8 \pm 3.1$ & 0 & $0.6 \pm 0.5$ \\
\hline nit mutant inoculum ${ }^{\mathrm{e}}$ & 0 & 0 & 0 & 0 & 0 \\
\hline Field soil + nit $\left(\right.$ low density) ${ }^{\mathrm{f}}$ & $77.4 \pm 1.7$ & $23.4 \pm 4.5$ & $0.2 \pm 0.4$ & 0 & $0.2 \pm 0.4$ \\
\hline Field soil + nit (high density) ${ }^{\mathrm{g}}$ & $38.6 \pm 10.0$ & $4.8 \pm 2.4$ & 0 & $0.2 \pm 0.4$ & $0.2 \pm 0.4$ \\
\hline
\end{tabular}

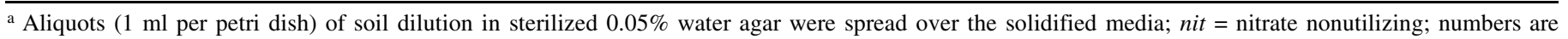
means of five replicates.

b $\mathrm{KM}=$ Komada's Fusarium-selective medium (7) with reduced pentachloronitrobenzene (75\% wettable powder) concentration (0.25 g/liter of the medium).

c Colonies of Fusarium spp. per petri dish \pm standard deviation (SD).

d Field soil; 200-fold dilution.

e Nit mutant inoculum (strain M2-1 incubated in sterilized soil); 2,000-fold dilution.

${ }^{\mathrm{f}}$ Field soil (19.8 g) amended with $0.2 \mathrm{~g}$ of the above nit inoculum; 200-fold dilution.

$\mathrm{g}$ Field soil (18 g) amended with $2 \mathrm{~g}$ of the above nit inoculum; 200-fold dilution.

${ }^{\text {h }}$ Colonies of fungi other than Fusarium spp. per petri dish \pm SD. 
formula $\log ([\mathrm{CFU} / \mathrm{g}$ of dry soil $]+1)$. Wilt data expressed as percentages were divided by 100 and square roots obtained for arcsine transformation before analysis. Data were analyzed by analysis of variance (ANOVA) and, when a significant $(P<0.05)$ $F$ value was observed, Student's $t$ tests were used to compare differences between two treatment means. Tukey-Kramer's method was used to compare multiple treatment means.

\section{RESULTS}

Media selectivity and rate of propagule recovery. Similar results were obtained from the two experiments to check media performance in selectivity and recovery of Fusarium propagules (Tables 2 and 3; Fig. 1). Naturally occurring Fusarium spp. in field soil did not grow at all on MMCPA, CMP, or CGMBP.

TABLE 3. Number of colonies of nit mutant Fusarium oxysporum, wild-type Fusarium spp., and other fungi on five selective media (second experiment) ${ }^{\mathrm{a}}$

\begin{tabular}{|c|c|c|c|c|c|}
\hline Soil sample & MMCPA & CMP & CGMBP & GMBP & $\mathrm{KM}^{\mathrm{b}}$ \\
\hline \multicolumn{6}{|l|}{ Fusarium spp. ${ }^{c}$} \\
\hline Field soild ${ }^{\mathrm{C}}$ & 0 & 0 & 0 & $52.8 \pm 4.2$ & $54.2 \pm 6.3$ \\
\hline nit mutant inoculum ${ }^{\mathrm{e}}$ & $62.6 \pm 11.6$ & $58.8 \pm 3.9$ & $52.6 \pm 12.8$ & 0 & $65.4 \pm 8.5$ \\
\hline Field soil + nit (high density)g & $71.8 \pm 10.2$ & $83.4 \pm 8.2$ & $86.0 \pm 8.9$ & $54.2 \pm 5.8$ & $153.8 \pm 20.8$ \\
\hline \multicolumn{6}{|l|}{ Other fungi ${ }^{\mathrm{h}}$} \\
\hline Field soil $^{\mathrm{d}}$ & $40.2 \pm 3.9$ & $1.4 \pm 0.5$ & 0 & $11.4 \pm 4.0$ & $5.6 \pm 0.5$ \\
\hline nit mutant inoculum ${ }^{\mathrm{e}}$ & 0 & 0 & 0 & 0 & 0 \\
\hline
\end{tabular}

a Aliquots $(0.7 \mathrm{ml}$ per petri dish) of soil dilution in sterilized $0.05 \%$ water agar were spread over the solidified media; nit $=$ nitrate nonutilizing; numbers are means of five replicates.

${ }^{\mathrm{b}} \mathrm{KM}=$ Komada's Fusarium-selective medium (7) with reduced pentachloronitrobenzene (75\% wettable powder) concentration $(0.25 \mathrm{~g} /$ liter of the medium).

c Colonies of Fusarium spp. per petri dish \pm standard deviation (SD).

d Field soil; 100-fold dilution.

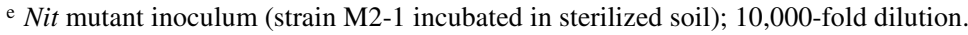

${ }^{\mathrm{f}}$ Field soil $(39.9 \mathrm{~g})$ amended with $0.1 \mathrm{~g}$ of the above nit inoculum; 100 -fold dilution.

$\mathrm{g}$ Field soil $(39 \mathrm{~g})$ amended with $1 \mathrm{~g}$ of the above nit inoculum; 100 -fold dilution.

${ }^{\mathrm{h}}$ Colonies of fungi other than Fusarium spp. per petri dish \pm SD.

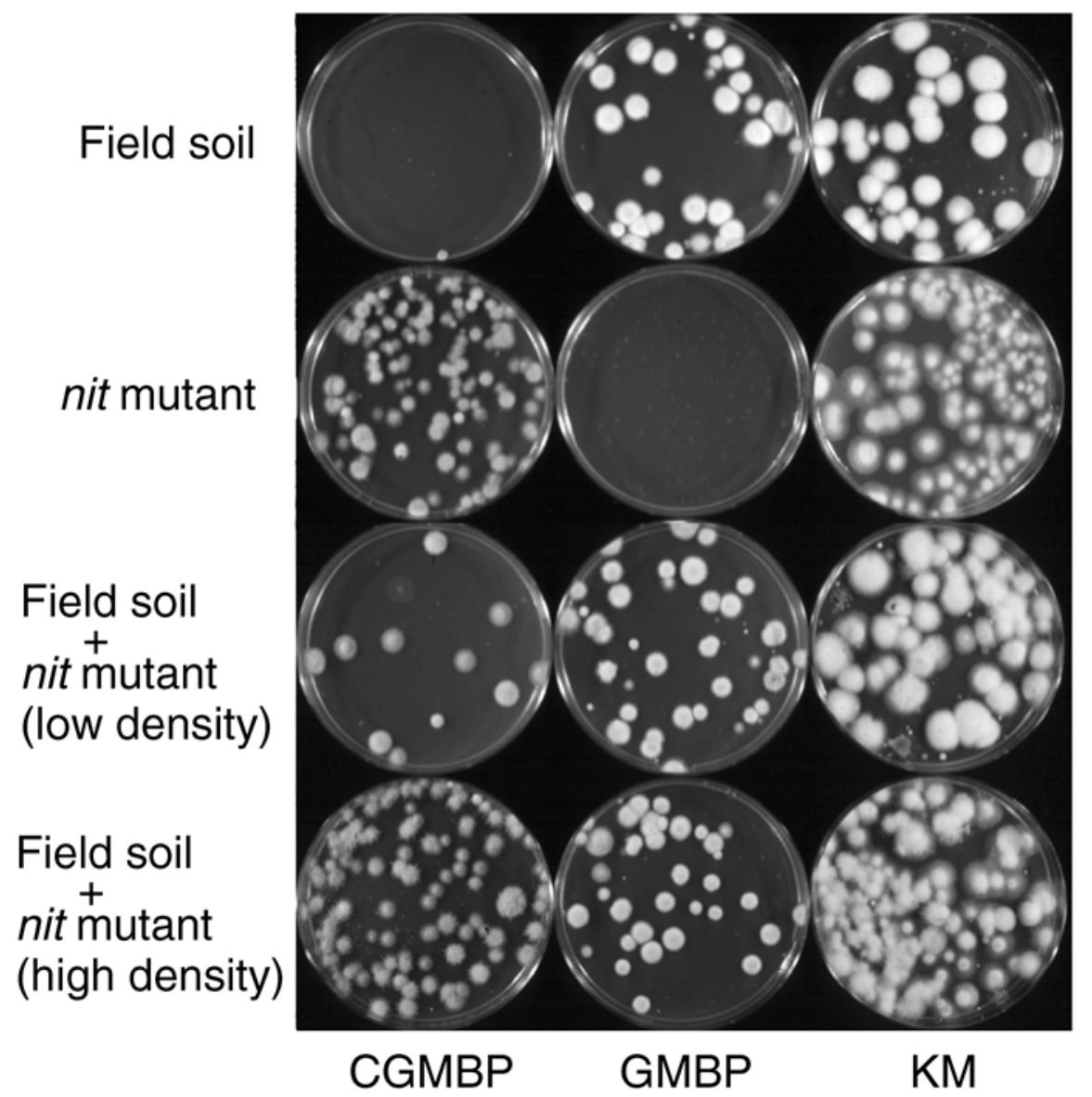

Fig. 1. Colony formation of nitrate-nonutilizing (nit) mutant Fusarium oxysporum and wild-type Fusarium spp. in soil on three selective media (first experiment). Samples ( $1 \mathrm{ml}$ per petri dish) of each soil dilution in sterile $0.05 \%$ water agar were spread over solidified media and incubated for 10 days at $25^{\circ} \mathrm{C}$. Soil samples from top to bottom are: field soil (200-fold-dilution solution); nit mutant inoculum (strain M2-1 incubated in sterilized soil, 2,000-fold-dilution solution); field soil (19.8 g) amended with $0.2 \mathrm{~g}$ of the described nit inoculum (200-fold-dilution solution); field soil (18 g) amended with $2 \mathrm{~g}$ of the nit inoculum (200-fold-dilution solution). Media are from left to right: CGMBP (nit mutant-selective medium); GMBP (wild-type Fusarium-selective medium); KM (Komada's Fusarium-selective medium [7] with reduced pentachloronitrobenzene (75\% wettable powder) concentration [0.25 g/liter of the medium]). Note that nit mutants produced colonies on CGMBP, wild-type Fusarium spp. produced colonies on GMBP, and both did on KM. 
Selectivity (suppression of colony formation of other fungi) increased, in order, on MMCPA, CMP, and CGMBP. Propagule recovery of nit mutant inoculum on these media was nearly comparable to KM, although the average number of colonies was 19.6 to $22.0 \%$ lower on CGMBP compared with KM. On GMBP, colonies of nit mutants grew very weakly and were barely visible for lack of available nitrogen source, facilitating the counting of wild-type Fusarium colonies. To confirm phenotypes of Fusarium colonies on CGMBP and GMBP, 50 randomly chosen colonies arising from field soil infested with a low density of nit mutants were transferred to Fusarium minimal medium (MM) (17) containing nitrate as the sole nitrogen source. All 50 of the tested Fusarium colonies on CGMBP proved to be nit mutants, as indicated by thin expansive growth on MM, and all 50 tested $F u$ sarium colonies on GMBP were wild type. Thus, the population densities of the added nit mutant and wild-type Fusarium spp. could be determined separately using these media.

Proliferation of nit mutant pathogen in hot water-, chloropicrin-, and non-treated soils. To examine the influence of hot water and chloropicrin treatments on the proliferation of the patho-
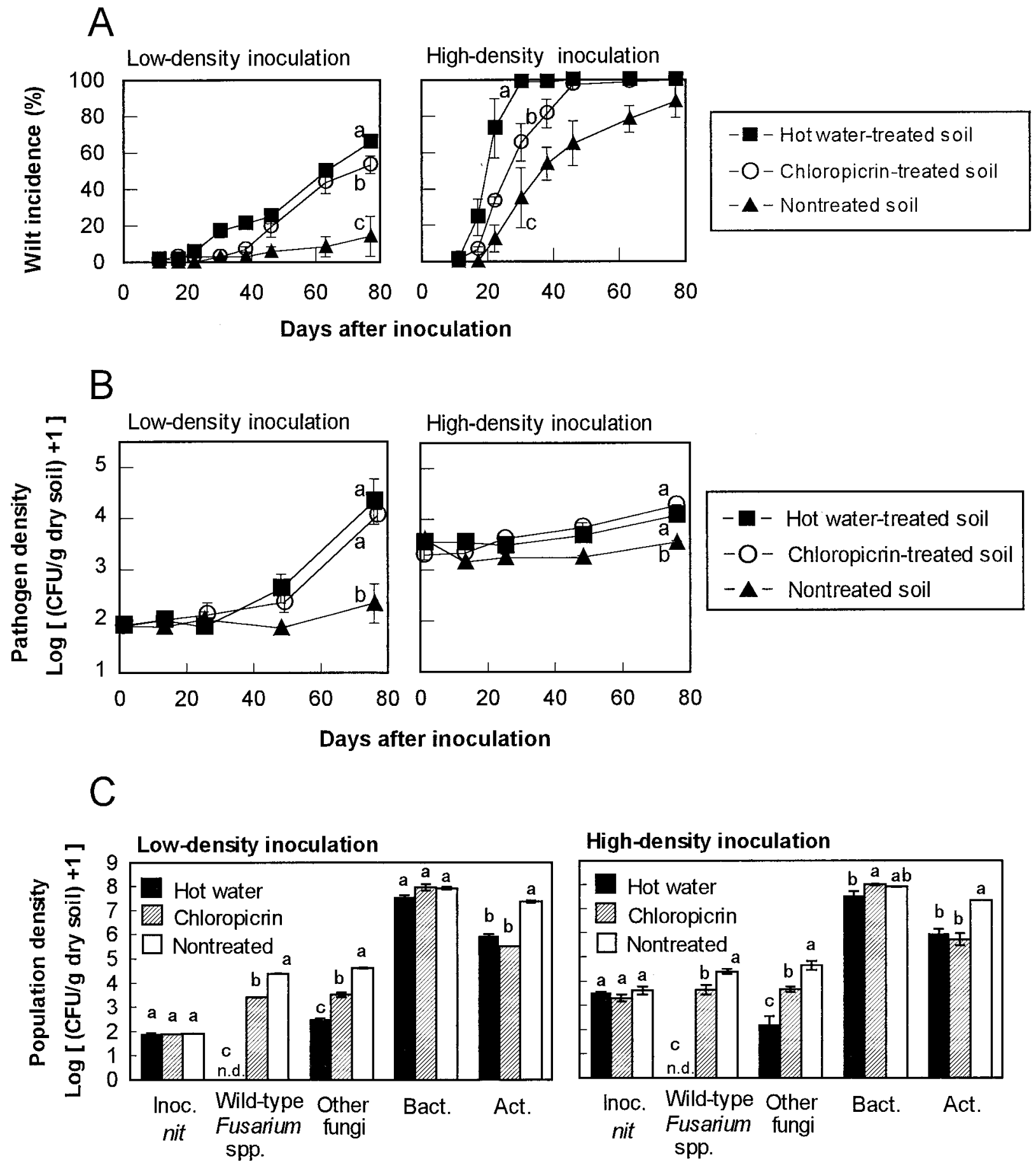

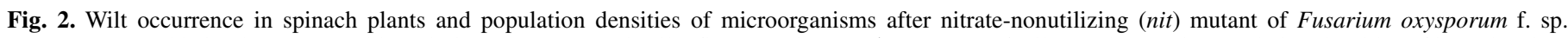

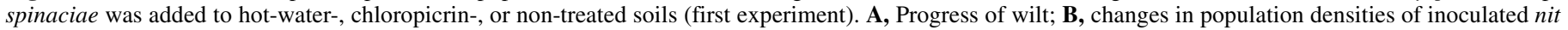

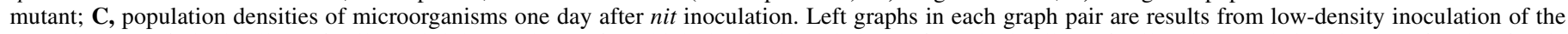

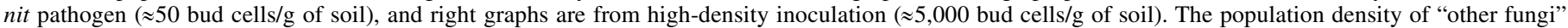

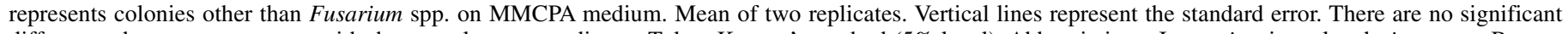

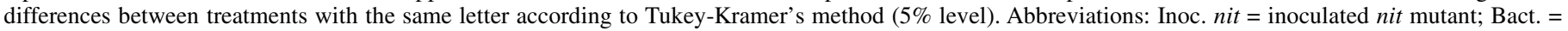
bacteria; Act. $=$ actinomycetes $;$ and n.d. $=$ not detected. 
gen introduced after the treatments, the nit mutant pathogen was added to the treated soil and nontreated field soil (raw soil). Spinach wilt developed faster and more severely in hot-water- and chloropicrin-treated soil than in raw soil (Figs. 2A and 3A).
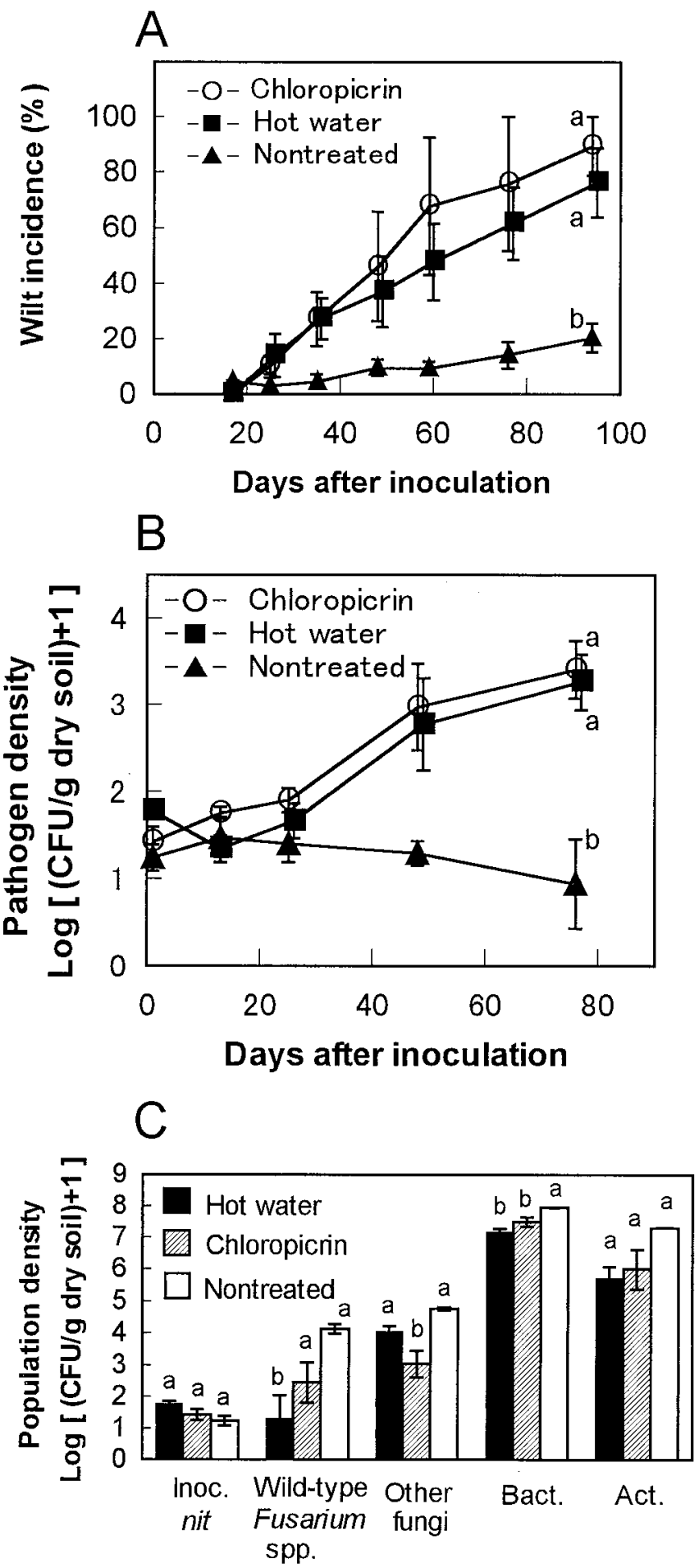

Fig. 3. Wilt occurrence in spinach plants and population densities of microorganisms after nitrate-nonutilizing (nit) mutant Fusarium oxysporum f. sp. spinaciae was inoculated into hot-water-, chloropicrin-, or non-treated soils (second experiment). A, Progress of wilt; $\mathbf{B}$, changes in population densities of inoculated nit mutant; $\mathbf{C}$, population densities of microorganisms 1 day after nit inoculation. The inoculation density of the nit pathogen was $\approx 50$ bud cells/g of soil. The population density of "other fungi" represents colonies other than Fusarium spp. on PAC medium. Mean of three replicates. Vertical lines represent the standard error. There are no significant differences between treatments with the same letter according to Tukey-Kramer's method (5\% level). Abbreviations: Inoc. nit $=$ inoculated nit mutant; Bact. = bacteria; Act. $=$ actinomycetes; and n.d. $=$ not detected .
When the pathogen was inoculated at a low density $(\approx 50$ bud cells/g of soil), pathogen growth and wilt occurrence was very limited until $\approx 25$ days after inoculation in all treatments (Fig. 2A and B, left graph; Fig. 3A and B). Thereafter, the pathogen proliferated rapidly in hot-water- and chloropicrin-treated soils, but grew very slowly or not at all in raw soil, with wilt following a similar pattern.

When the pathogen was inoculated at a high density $(\approx 5,000$ bud cells/g of soil), most spinach plants had wilted by 46 days after inoculation in hot-water- and chloropicrin-treated soil, while wilt occurrence was delayed in raw soil. The pathogen population did not increase detectably in raw soil and increased gradually up to $\approx 10^{4} \mathrm{CFU} / \mathrm{g}$ of dry soil in hot-water- and chloropicrin-treated soils (Fig. 2A and B, right graph).

In all cases, the fungal and bacterial flora of disinfested soil obviously was simplified, judging from the morphology of colonies on media. The proportion of Trichoderma spp. was higher after chloropicrin treatments. In the first experiment, the populations of wild-type Fusarium spp. and other fungi were significantly lower in disinfested soils compared with those in raw soil. The population of actinomycetes was $>10$ times greater in raw soil than in the other two soil plots (Fig. 2C). A similar tendency was observed in the second experiment (Fig. 3C); however, the difference was not always significant because of the rather large variance that may have resulted from imperfect disinfesting of one field plot in each of the three replicate plots of the hot water and chloropicrin treatments.

Antagonistic effect of nonpathogenic $F$. oxysporum on pathogen proliferation in sterilized soil. To examine the possibility of competition between populations of PF and NPF in soil, we studied their population dynamics in more controlled conditions (i.e., in sterilized soil in flasks). An example of soil-dilution plating from the second experiment is shown in Figure 4, and changes in population densities of PF and NPF in the three similar experiments are shown in Figure 5. When incubated alone, PF (nit mutant) proliferated rapidly, reaching a density of 1.01 to $3.82 \times$ $10^{5} \mathrm{CFU} / \mathrm{g}$ of dry soil in 13 days (Fig. 5A and C). When NPF (wild type) was added to soil 8 days before PF, PF proliferation was significantly suppressed, and PF did not change significantly, remaining at approximately the initial density (Fig. 5B and D). Furthermore, in the third experiment, in which a wild type was used as PF and nit mutant as NPF (Fig. 5E and F), PF proliferation also was suppressed as in the previous two experiments. Thus, the nit mutant is not competitively inferior to wild type because of its lack of nitrate utilization. The density of PF added later did not affect NPF proliferation (Fig. 5B, D, and F). No fungal or bacterial contamination of the soil in flasks was detected throughout the experiments.

\section{DISCUSSION}

Nit mutants of $F$. oxysporum most commonly have been used to define vegetative compatibility groupings of this important plant pathogen $(5,6)$ since the first such report by Puhalla in 1985 (17). Although Hadar et al. (3) developed a chlorate-containing selective medium for chlorate-resistant nit mutants in 1989 and suggested the possibility of using nit mutants as marker strains for ecological studies of $F$. oxysporum, only a few studies $(18,24)$ actually have used nit mutants for this purpose. As shown in our experiments, the population density of the nit mutant pathogen could be measured using nit mutant-selective media MMCPA, CMP, and CGMBP. CGMBP had the highest selectivity of the three media. The miconazole nitrate in CMP and CGMBP greatly contributes to their high selectivity. The population density of wild-type NPF was countable on GMBP. Combining CGMBP and GMBP would be especially useful for analyzing population dynamics of pathogenic and nonpathogenic $F$. oxysporum by using a nit mutant for one strain and a wild type for another. However, 
for unknown reasons, sometimes fewer colonies than expected grew on MMCPA, CMP, and CGMBP (T. Takehara, unpublished data). A decrease in water content and light exposure during the preservation of those media may adversely affect Fusarium propagule recovery. Therefore, after pouring and solidifying media in plates, plates should be stored in a sealed box in a dark, cool place and used within a month. Recovery of nit mutant propagules on the media also should be compared each time of use to that on a more reliable medium, such as PAC, for Fusarium detection. Some nit isolates also may be more susceptible to antifungal agents such as miconazole nitrate and PCNB in these media; decreasing the agents may be useful for obtaining higher recovery. The choice of medium to detect a specific nit mutant should be determined according to the recovery rate of the nit mutant on those media and the population density of other fungi in a particular soil.

It may be argued that nit mutants are not truly representative of wild-type $F$. oxysporum, because they cannot use nitrate. However, we have reported previously that nit mutants share many of the properties, such as growth, pathogenicity, benomyl sensitivity, and survival in soil, of wild-type strains (23). Many types of nitrogen sources in soil are available to nit mutants, and no difference in saprophytic ability has been reported so far between nit mutants and wild-type strains of $F$. oxysporum. Moreover, in field experiments in plastic houses, population densities of nit mutants of $F$. oxysporum f. sp. spinaciae and f. sp. lycopersici were monitored for 2 years and correlated with disease severity (T. Takehara, unpublished data). However, a nit mutant of Colletotrichum gloeosporioides was reported to be less competitive than the wild type on northern joint vetch (a leguminous weed) (28). Thus, more study is needed on the saprophytic ability of nit mutants in raw soil.

Presently, the number of years nit mutants can survive in field soil is not known. Nit mutant-infested soil, media, and infected plants must be sterilized before disposal to avoid mutant dispersion, because once nit mutants become present in natural soil, they no longer can be used as marker strains. For the same reason, extreme care should be taken when using nit mutants in field experiments, and nit mutants should not be used in open fields.

Hot-water disinfestation and chloropicrin fumigation of soil are highly effective against Fusarium wilt of spinach (8). In field soil infested with the pathogen, the pathogen was killed by using hot water to elevate soil temperature to $>55^{\circ} \mathrm{C}$ at a depth of 20 to $30 \mathrm{~cm}$ and holding that temperature for 3 to $4 \mathrm{~h}$. However, the possibility of proliferation of the remaining or reintroduced pathogen after disinfestation has not been examined. We used a nit

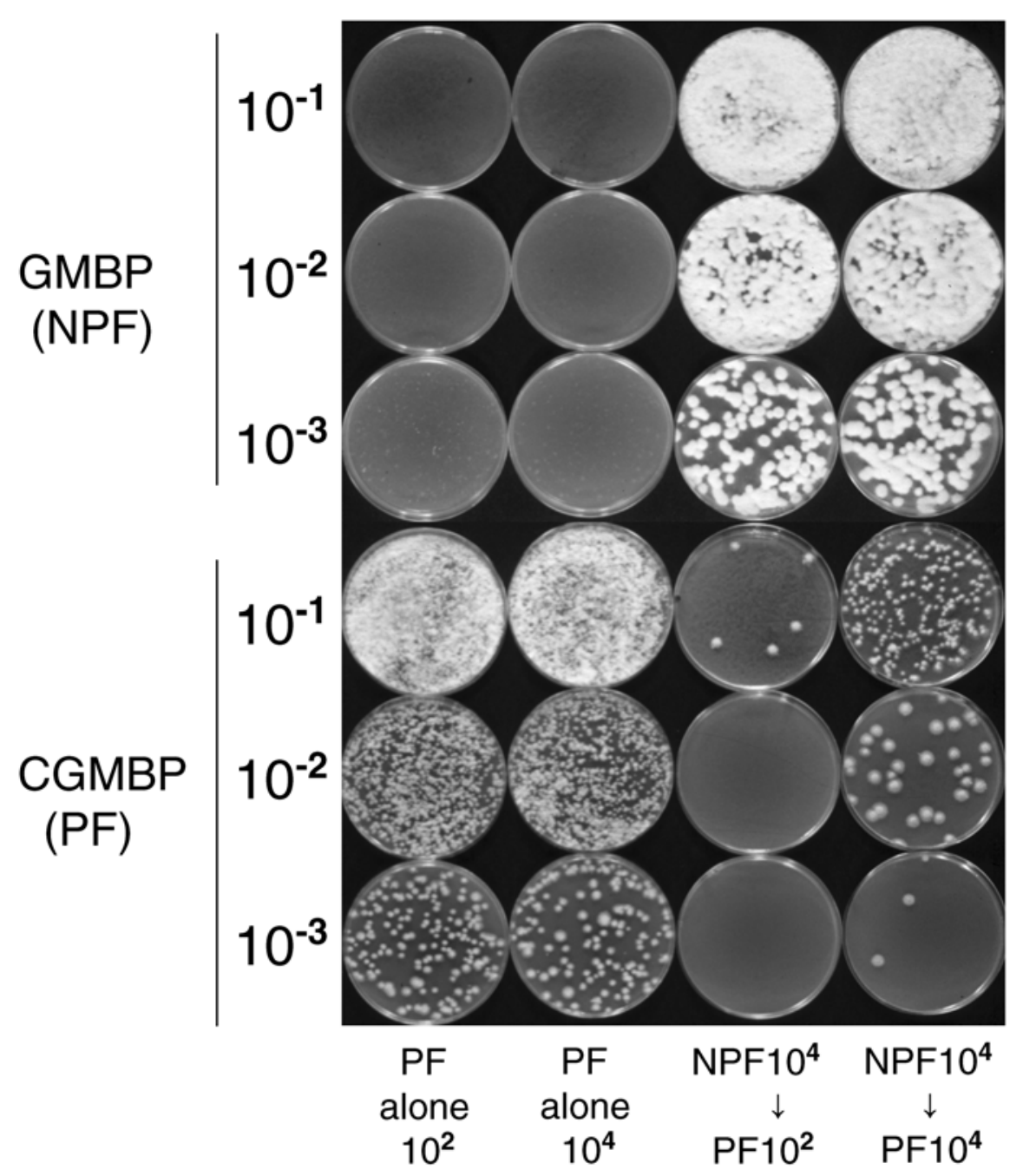

Fig. 4. Influence of the pretreatment of nonpathogenic Fusarium oxysporum (NPF, strain S1HI1-W) on the proliferation of $F$. oxysporum f. sp. spinaciae (PF, nitrate-nonutilizing [nit] mutant M2-1) in sterilized soil. Soil dilution plates (10 days after plating) from the second experiment 13 days after inoculation of PF. From left column to right, soil samples were: PF alone (initial density: $10^{2}$ bud cells/g of dry soil); PF alone (initial density: $10^{4}$ bud cells/g of dry soil); NPF was treated at $10^{4}$ bud cells/g of dry soil 8 days before PF inoculation at $10^{2} \mathrm{CFU} / \mathrm{g}$ of dry soil; NPF was treated at $10^{4}$ bud cells/g of dry soil 8 days before PF inoculation at $10^{4}$ bud cells/g of dry soil. Soil samples at $10^{-1}, 10^{-2}$, and $10^{-3}$ dilutions were plated on GMBP (wild-type Fusarium-selective medium, upper three lines) and on CGMBP (nit mutant-selective medium, lower three lines). Colonies of pretreated NPF (wild type) are growing on GMBP, and colonies of PF (nit) inoculated later are growing on CGMBP. Note that PF densities in NPF-treated soils are significantly lower than those in PF-alone soils. 

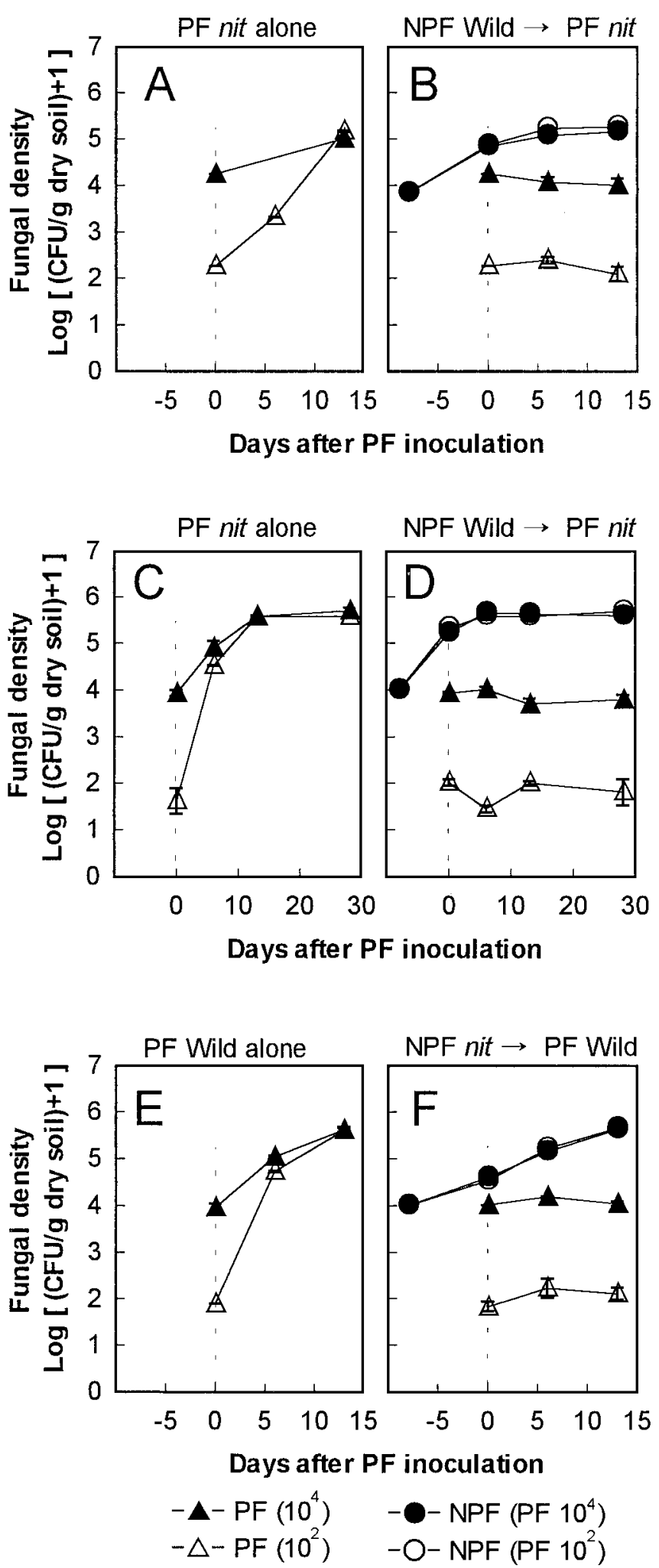

Fig. 5. Influence of the pretreatment of nonpathogenic Fusarium oxysporum (NPF) on the proliferation of $F$. oxysporum $\mathrm{f}$. sp. spinaciae (PF) in sterilized soil. $\mathbf{A}$ and $\mathbf{B}$, first experiment; $\mathbf{C}$ and $\mathbf{D}$, second experiment; $\mathbf{E}$ and $\mathbf{F}$, third experiment. A to D, Nitrate-nonutilizing (nit) mutant of PF (M2-1) and wild type of NPF (S1HI1-W) were used. E and F, Wild type of PF (Spin-2) and nit mutant of NPF (NA-12) were used. A, C, and E, PF was incubated alone (initial density: $10^{2}$ or $10^{4}$ bud cells/g of dry soil); B, D, and F, NPF was treated at $10^{4}$ bud cells/g of dry soil 8 days before PF inoculation at $10^{2}$ or $10^{4}$ bud cells/g of dry soil. Mean of two replicates. Vertical lines represent the standard error. $\mathbf{A}$ and $\mathbf{B}$, Initial densities for PF and $\mathbf{B}, \mathbf{D}$, and $\mathbf{F}$, initial densities for NPF are estimated values calculated from the number of incorporated bud cells. mutant to study population dynamics of the pathogen in disinfested soils that contained relatively limited diversity of microorganisms, and demonstrated rapid proliferation of the pathogen compared with raw soil.

The pathogen in large root residues of spinach survives chloropicrin fumigation (4). Thus, survivors in roots after chloropicrin treatment may be an important source of reinfestation. Although rapid reinfestation with the pathogen in hot-water-treated fields has not been observed yet, care should be taken to avoid pathogen reintroduction.

To examine the possibility of delaying pathogen proliferation with preinoculation of different microorganisms, we pretreated soil with a nonpathogenic strain of F. oxysporum (NPF strain S1HI1W) 7 days before the pathogen (PF) using a high NPF/PF density ratio. Spinach wilt then was suppressed (T. Takehara, unpublished data). Because the NPF strain is not antagonistic against PF in dual culture on PSA plates, the disease suppression is thought to be caused by competition for nutrition or infection sites or by induced systemic resistance $(10,11,15)$. In flasks, NPF clearly suppresses PF proliferation but cannot reduce the density of already existing PF. Because NPF at least delays pathogen proliferation, introducing a highly proliferative NPF (12) after soil disinfestation may be useful.

\section{ACKNOWLEDGMENTS}

We thank Y. Akasaka, Iwate Horticultural Experiment Station, Japan (presently Kuji Regional Development Bureau, Iwate Pref., Japan) for contributing the nonpathogenic $F$. oxysporum isolate S1HI1-W used in this study.

\section{LITERATURE CITED}

1. Akasaka, Y., Takehara, T., Komoto, Y., and Kuniyasu, K. 1993. Recovery of the nitrate-nonutilizing (nit) mutants of Fusarium oxysporum f. sp. spinaciae and nonpathogenic $F$. oxysporum and their reisolation from soil. (In Japanese.) Annu. Rep. Plant Prot. N. Jpn. 44:61-64.

2. Fiely, M. B., and Correll, J. C. 1995. Vegetative compatibility, pathogenicity, and virulence diversity of Fusarium oxysporum recovered from spinach. Plant Dis. 79:990-993.

3. Hadar, E., Katan, J., and Katan, T. 1989. The use of nitrate-nonutilizing mutants and a selective medium for studies of pathogenic strains of Fusarium oxysporum. Plant Dis. 73:800-803.

4. Kajihara, H., Takehara, T., Takagi, Y., Nakayama, T., Saitoh, H., Sato, T., Sumida, Y., and Inoue, T. 1999. The effect of wilt-diseased spinach root residues on the performance of soil fumigation. (Abstr.) (In Japanese.) Kyushu Plant Prot. Res. 45:134.

5. Katan, T. 1999. Current status of vegetative compatibility groups in Fusarium oxysporum. Phytoparasitica 27:51-64.

6. Katan, T. 1999. Current status of vegetative compatibility groups in Fusarium oxysporum: Supplement. Phytoparasitica 27:273-277.

7. Komada, H. 1975. Development of a selective medium for quantitative isolation of Fusarium oxysporum from natural soil. Rev. Plant Prot. Res. 8:114-125.

8. Kuniyasu, K., Takehara, T., Chiba, T., Uehara, K., and Oohata, A. 1993. Control of spinach Fusarium wilt, Fusarium oxysporum f. sp. spinaciae, by soil sterilization with hot water injection. (In Japanese.) Proc. KantoTosan Plant Prot. Soc. 40:97-99.

9. Kuniyasu, K., and Takeuchi, S. 1986. Control of Fusarium wilt of tomato by soil sterilization with hot water. (In Japanese, with English summary.) Bull. Veg. Ornamen. Crops Res. Stn. Ser. A. 14:141-148.

10. Larkin, R. P., and Fravel, D. R. 1999. Mechanisms of action and doseresponse relationships governing biological control of Fusarium wilt of tomato by nonpathogenic Fusarium spp. Phytopathology 89:1152-1161.

11. Mandeel, Q., and Baker, R. 1991. Mechanisms involved in biological control of Fusarium wilt of cucumber with strains of nonpathogenic Fusarium oxysporum. Phytopathology 81:462-469.

12. Nagao, H., Couteaudier, Y., and Alabouvette, C. 1990. Colonization of sterilized soil and flax roots by strains of Fusarium oxysporum and Fusarium solani. Symbiosis 9:343-354.

13. Naiki, T., and Morita, Y. 1983. The population of spinach wilt fungus, Fusarium oxysporum f. sp. spinaciae, and the wilt incidence in soil. Ann. Phytopathol. Soc. Jpn. 49:539-544.

14. Nash, S. M., and Snyder, W. C. 1962. Quantitative estimation of propagules of the bean root rot Fusarium in field soil by plate counts. Phytopathology 52:567-572. 
15. Ogawa, K., and Komada, H. 1985. Biological control of Fusarium wilt of sweet potato with cross-protection by prior inoculation with nonpathogenic Fusarium oxysporum. JARQ 19:20-25.

16. Ogura, H., Morimoto, T., and Taketani, K. 1966. Studies on saprophytic behavior of soil borne pathogenic fungi. III. On the change of microflora in soil treated with soil fumigants. (In Japanese, with English summary.) Res. Rep. Kochi Univ. 15, Nat. Sci. II 12:101115.

17. Puhalla, J. E. 1985. Classification of strains of Fusarium oxysporum on the basis of vegetative compatibility. Can. J. Bot. 63:179-183.

18. Rekah, Y., Shtienberg, D., and Katan, J. 1999. Spatial distribution and temporal development of Fusarium crown and root rot of tomato and pathogen dissemination in field soil. Phytopathology 89:831-839.

19. Shimonagane, K., Matsuda, A., and Watanabe, B. 1965. Studies on field application of soil fungicides. IV. Reinfestation with Fusarium oxysporum after fumigation with chloropicrin. (Abstr.) (In Japanese.) Ann. Phytopathol. Soc. Jpn. 30:103.

20. Takehara, T., Hagiwara, H., and Kuniyasu, K. 1995. Selective quantification of nit mutant and wild-type Fusarium oxysporum in the soil. (Abstr.) (In Japanese.) Ann. Phytopathol. Soc. Jpn. 61:606.

21. Takehara, T., and Kuniyasu, K. 1994. Use of nitrate-nonutilizing mutants in ecological studies of Fusarium diseases. I. Formation of nit mutants from some formae speciales of Fusarium oxysporum. (In Japanese, with English summary.) Ann. Phytopathol. Soc. Jpn. 60:699-704.
22. Takehara, T., and Kuniyasu, K. 1994. Use of nitrate-nonutilizing mutants in ecological studies of Fusarium diseases. II. Isolation of nitrate-nonutilizing mutants of Fusarium oxysporum on selective media. (In Japanese, with English summary.) Ann. Phytopathol. Soc. Jpn. 60:705-710.

23. Takehara, T., and Kuniyasu, K. 1995. Use of nitrate nonutilizing mutants in ecological studies of Fusarium diseases. III. Growth, benomyl sensitivity, pathogenicity, and stability of nit mutants of Fusarium oxysporum compared to wild-type strains. Ann. Phytopathol. Soc. Jpn. 61:541-548.

24. Takehara, T., and Kuniyasu, K. 1997. Use of nitrate nonutilizing mutants in ecological studies of Fusarium diseases. IV. Seed transmission of Fusarium oxysporum f. sp. lycopersici race 2. (In Japanese, with English summary.) Bull. Natl. Agric. Res. Cent. 26:1-13.

25. Tonso, N. L., Matheson, V. G., and Holben, W. E. 1995. Polyphasic characterization of a suite of bacterial isolates capable of degrading 2,4D. Microbiol. Ecol. 30:3-24.

26. Tsao, P. H. 1970. Selective media for isolation of pathogenic fungi. Annu. Rev. Phytopathol. 8:157-186.

27. Ueda, S., Komada, H., and Yamamoto, H. 1994. The improvement of selective medium for nitrate-nonutilizing mutants of Fusarium oxysporum. (Abstr.) (In Japanese.) Ann. Phytopathol. Soc. Jpn. 60:771.

28. Yang, X. B., and TeBeest, D. O. 1995. Competitiveness of mutant and wild-type isolates of Colletotrichum gloeosporioides f. sp. aeschynomene on northern joint vetch. Phytopathology 85:705-710. 